\title{
COVID-19: Mental Health Issues and Impact on Different Professions
}

\author{
Diksha Purushottam Gourkhede*, Karthikeyan Ravichandran, Srinivas Kandhan, \\ Vemula Prasastha Ram, B. Dhayananth, G. K. Megha and M. Suman Kumar
}
Division of Veterinary Public Health, ICAR-Indian Veterinary Research Institute (IVRI), Izatnagar, Bareilly - 243 122, Uttar Pradesh, India

*Corresponding author

\section{Keywords}

COVID-19, Mental health, Psychology, Stigma, Lockdown, Stress, Anxiety, Depression

\section{Article Info}

Accepted:

22 June 2020

Available Online:

10 July 2020

\section{A B S T R A C T}

The COVID-19 pandemic caused by SARS-CoV-2 has left a massive impact on the way of living and interaction between people. Containment strategies implemented at regional, national, and global levels have radically transformed everyone's personal and professional lives. Many people are in front-line services, some are caring for those who are vulnerable and some are vulnerable themselves. The pandemic has created a mental toll leading to high anxiety and uncertainty among individuals and the society as a whole about how life will turn out in the upcoming future. The virus may not infect each person but nearly everyone will experience different levels of psychological distress undoubtedly, which shows the significant psychological impact caused by COVID-19. The impact may be different for every individual and may vary from 'severe' in mental illness patients and 'sufficient' in mentally sound individuals. The need of the hour is to strengthen our mental health system to prepare for the inevitable challenges that loom at the end of this pandemic. In this context, an attempt has been made to focus onthe issues of mental health, impact of the pandemic on mental health of various professionals, social stigma-related issues, evaluation of mental parameters, and remedies to overcome them. Many countries around the world have been able to control the outbreak within their borders and have taken necessary steps to restore normalcy in terms of economy, however, it is equally important to forward mental health issues.

\section{Introduction}

The World Health Organization (WHO) defines health as "a state of complete physical, mental, and social well-being and not merely the absence of disease or infirmity" (Constitution WHO, 2005). Along with physical health, mental health is also very important to consider an individual as completely healthy and both are closely associated through various mechanisms (Funk et al., 2005). Mental health is often a misunderstood and neglected domain. Mental health is described by WHO as "a state of well-being in which the individual realizes his or her own abilities, can cope with the normal stresses of life, can work productively and fruitfully, and can contribute to his or her community". Since 1950 many studies have reinforced the fact that medically sick patients 
with negative attitudes may have adverse outcomes than those with more positive attitudes (Giltay et al., 2004). Even before the onset of COVID-19, the mental health system was in a hapless condition as countries around the world spent only $2 \%$ of their health budget on mental health on an average (Fig. 1) although the estimated loss of global economy was around USD 1 trillion per year due to depression and anxiety (UN, 2020).

In December 2019, Wuhan city, China evinced an outbreak of a novel coronavirus and within a short period it has spread worldwide (Carlos et al., 2020; Du Toit, 2020; Huang et al., 2020). On March 11, 2020, WHO declared the outbreak of novel coronavirus (COVID-19) as a global pandemic owing to its high contagiousness and life-threatening outcomes (Cucinotta and Vanelli, 2020). Characterizing the word 'pandemic', WHO's Director General specified that the term should not be used carelessly or lightly and if it is misused, it may lead to a groundless fear or acceptance that the fight is over, which may lead to unavoidable suffering and death (WHO, 11 March 2020). As it emerges as a global health emergency, strict public health measures have been implemented to limit the spread of the infection ultimately leading to a collective impact on humankind (Adhikari et al., 2020). COVID-19 causes both physical illness, which is more serious and fatal in immunosuppressed individuals, and mental distress, which is even more serious in mentally ill people (Kim and Su, 2020).

National Health Centre, China reported that nearly 300 patients having serious mental illness turned positive for COVID-19 (NHC China, 2020). In South Korea, at a local psychiatric ward, out of 103 patients, 102 tested positive for COVID-19 (Republic of Korea, 2020). Numerous reports from all over the world have focussed on the devastating impact of the pandemic on mental health (Fig.2). Medical staff working on the frontlines to fight COVID-19 is at a high risk of developing infection (Lima et al., 2020). Specific population groups such as the frontline staff and even the common public is dreadful of how long the pandemic will last, coupled with the fear about their loved ones getting infected, the situation has made a wide range of psychological impact on different strata of the population. COVID-19 pandemic is being touted to add to the existing burden on the mental health systems around the world, which is already fragile due to lack of manpower and financial support.

\section{Effect of COVID-19 on people with mental illness}

Each person will respond to the threats of COVID-19 either directly or indirectly and hence one's adaptive and automatic responses to threats can increase mental distress. People already governing mental health issues and emotional difficulties like fear, sadness, and anger (relevant psychological reactions to uncertainty) may face additional challenges and complexity together with environmental and physical factors (Kim and Su, 2020). It is necessary to consider the impact of the pandemic on people with severe and enduring mental illnesses such as post-traumatic stress disorder (PTSD) resulting from several traumas, obsessive-compulsive disorder, schizophrenia, personality disorders, bipolar affective disorder, and severe forms of depression and anxiety conditions(Benjamin and Druss, 2020). There are multiple reasons for the high impact of COVID-19 on people with existing mental illness like:

Escalating panic due to the rapid spread of the disease can impact those who struggle with paranoia, a core symptom of schizophrenia (Ho et al., 2020)

Continuous lockdown and news feed of scary 
events are more likely to impact those who have experienced agony before (Wind et al., 2020)

Digital exclusion or reduced contact to social or public events

Severe mental illness people at a minimum of $40 \%$ will smoke, three times more than the general population. This addiction or health risk may increase in COVID19 (Lewis, 2020)

Other health behaviours such as physical activity, diet, and seeking healthcare are challenging for this group, even more so during COVID-19 (Cullen et al., 2020)

Individuals who are struggling socially, attending job-seeking courses, not interested in joining social gatherings, or exposing to factors like drugs, alcohol, and other selfabusing (Gunnell et al., 2020) behaviours may get some level of recess in a short time. However, the unavoidable consequences of extended isolation, uncertainty, and fear will be an important distressing mix for vulnerable individuals with pre-existing mental health conditions (Bao et al., 2020). Besides the people with existing mental illness, mentally sound persons are also vulnerable to psychological stress due to the pandemic.

\section{Psychology of COVID-19 affected people}

The mental health and psychological impact of COVID-19 on those who were infected should be recognized with care. The ones who have had a definite positive test or were showing obvious symptoms will have an escalated sense of anxiety about what is to come (Duan and Zhu, 2020). Most people experience either no illness or mild to moderate symptoms that place them in an extra level of self-isolation rather than requiring hospital care which may lead to additional psychological stress (Brooks et al., 2020). During hospital care, delirium is a concerning issue and results in both physical and mental distress. There is now evidence of COVID-19 delirium being a severe and troubling situation of altered mental state (Kotfis et al., 2020). It is the longer-term traumatic experience of having the most concerning illness. We know that a large proportion of critical care patients find it to be a traumatizing experience despite the lifesaving care they receive. For some individuals, the experience of being in hospital can be traumatizing, but for others, the experience of becoming ill - of being forced to realize that they are vulnerable - can also cause psychological distress. Further, with COVID-19 we are beginning to see that many individuals can have a slow recovery journey. The research study known into chronic health conditions that a boom and bust cycle of activity can follow a bout of illness - this is where individuals feel that they are on the mend; they push themselves in a flight toward health, only to be knocked back again, and this can be a disheartening experience (Kashyap, 2020).

\section{Impact of lockdown on mental health}

To contain the severity of COVID-19, many countries, including India announced lockdown. On 9 April, World economic forum had described the lockdown as the 'world's largest psychological crisis'. At the beginning of May, 2.6 billion people were estimated to be living in some sort of isolation or lockdown and this is possibly the largest psychological experiment ever (Kamm, 2020). Many of the people now are in quarantine may experience fear, depression, and anger (Brooks et al., 2020). The fear and panic among the general population all through the globe is spreading quicker than the infection. Emotional wellness is a genuine worry among the numerous functional issues we face. The adjustment in routine and sense of confinement could seriously affect our feeling of prosperity. Not every person's response will be the same to such stressful 
circumstances. Some groups may be more vulnerable than others to the psychosocial effects of pandemics (Holmes et al., 2020). A study was conducted to analyse the mental health covering 8000 people across the USA during the lockdown period with two waves of questions, one in late March and another in mid-April. It was found that compared to men, women were more vulnerable to mental health problems and the study proposed possible reasons for this impact (AdamsPrassal et al., 2020)

As it is occurring around the world, the new epidemic is vandalizing in India too. The entire nation of India was put under lockdown to break the transmission chain and control the spread of COVID-19. However, this physical restraint placed on the population has some untoward effects on their mental wellbeing (Kumar and Nayar, 2020; Gao et al., 2020). At the household level, various factors that contribute to mental stress are the shortage of resources at stock, fear of losing job, loss of daily wages, isolation from family or routine living group, etc. (Lee et al., 2020).

People have also taken towards procreation during this lockdown and UNFPA has estimated a total of 7 million unintended pregnancies due to disruption in access to contraceptives, which might ultimately result in abortions (PTI, 29 April 2020). People have also resorted to domestic violence, gender-based violence, online gaming (Singh, 2020), the effects of which can be expected sooner or later.

Ailing patients are at risk of losing adequate health care and lack of access to liquor had triggered withdrawal symptoms. At the professional level, many are concerned about job securities and pay-cuts. The corporate sector has been subjecting its employees to work-from-home mode of function, which may or may not be fruitful in terms of mental health (Chakrabarthi, 2020; IANS, 2020a). The production and marketing of various entrepreneurs have been affected significantly. Personnel engaged in healthcare, sanitation, and law and order management have been subjected to tremendous pressure on and off the workplace.

At the national level, India is staring at an economic challenge, which can further contribute to mental illness and increase suicide rates. A week into the lockdown, the number of mental illnesses skyrocketed by $20 \%$ according to a survey conducted by the Indian Psychiatry Society (Sharma and Subramanyam, 2020; Naik, 2020). In the long run an estimated 150 million people with preexisting mental conditions are at an increased risk (Vijayaraghavan and Singhal, 2020). In order to tackle this mental disaster, we need strong infrastructure and policy decisions towards mitigation and to provide adequate rehabilitation and support.

In a country like India, with the world's second-largest population, it is astonishing to see that there are only 9,000 psychiatrists for 1.3 billion people (Garg et al., 2019). Health authorities such as the World Health Organization (WHO, 18 March 2020) and the Ministry of Health and Family Welfare (MoHFW) of India have come up with considerations and suggestions to the public to handle mental stress related with COVID19.

Several NGOs, volunteer groups, and even some state governments (PTI, 18 April 2020) have taken up this task of establishing helpline portals to alleviate mental pain arising during this outbreak and lockdown. Further, these areas need to be strengthened with adequate framework, human and financial resources. 


\section{Corona phobia: A fear of pandemic or a pandemic of fear?}

Fear is a type of emotion that is triggered in response to a threat and is categorized into four domains to cotton on to corona pandemics (Ornell et al., 2020; Schimmenti et al., 2020). These domains include (a) fear of the body/fear for the body, (b) fear of significant others/fear for significant others, (c) fear of not knowing/fear of knowing and (d) fear of taking action/fear of inaction.

Fear of body explains the extreme cautiousness to slight body changes which in turn insinuates COVID-19 infection, while fear for the body considers the body as a treasure to be shielded against the pandemic disease. Due to such a fear regarding the body, people do not risk getting medical check-ups for certain non-communicable diseases or may undergo stress-related absenteeism in workplaces, as they fear contracting COVID-19 infection from hospitals or their working environment. In this scenario neither the physical health nor the mental health is secured. However, the body "keeps the score" (van der Kolk, 2015) regarding episodes which jeopardize our bodily and mental integrity.

The second domain of fear relates to interpersonal relationships which become impossible between and among families because of social distancing owing to the threats caused by COVID-19 pandemic. The disease may spread from the person to their loved ones and also from the loved ones to that person in contact and is explained in the second domain conversely.

Fear of not knowing/fear of knowing mainly verbalizes the information which is good to be known for some people and better left unknown for certain people. Such data regarding COVID-19 can be known, learned, and useful for prevention from the disease among some people while in some others this information creates nothing but panic through cyberchondria (Starcevic, 2017).

The fourth domain is a result of all the other three domains of fear which alternates and contrasts each other which at last may lead to an action or inaction. Susceptible people can't even take actions such as buying groceries, opening packages which explain the fear of taking action. On the flip side, certain others have the strong will to take action by passively posting videos, information related to the pandemics and alleviate the fear of inaction, but still, this may create social media addictive problems in the future.

Sense of fear is mainly created through viewing of certain video clips or going through false information related to COVID19 on social media (Love et al., 2020; The Telegraph, 2020). A case of suicide was reported in India wherein a fifty-year-old contracted some viral disease and wrongly suspected himself for corona after viewing clips on the internet and social media (Goyal et al., 2020). Such instances throw weight on the fact that deficit of information and sensationalized propaganda aggravated through breath-taking media headlines has augmented the health-related fears and phobias (Taylor and Asmundson, 2004).

People who depend on others for living are waiting with fear to handle the world in the post-corona situation (Asmundson and Taylor, 2020). For instance, blind people who always depend on their tactile sense will face a different world. In India alone, more than 2 million people are blind, which comprises one-third of the world blind population(39 million globally). They will face problems not only with touching any surface for fear of contracting the virus but also due to new constraints of social distancing which would restrict the outside world combatant towards helping them (Athar, 2020). 


\section{Social stigma associated with COVID-19}

Pandemics are often known to take a toll on mental health rather than the disease itself and COVID-19 is not an exception. According to UNICEF, "Social stigma in the context of health is the negative association between a person or group of people who share certain characteristics and a specific disease. In an outbreak, this may mean people are labelled, stereotyped, discriminated against, treated separately, and/or experience loss of status because of a perceived link with a disease" (UNICEF, WHO and IFRC, 2020). According to the CDC, "Stigma is discrimination against an identifiable group of people, a place, or a nation. Stigma is associated with a lack of knowledge about how COVID-19 spreads, a need to blame someone, fears about disease and death, and gossip that spreads rumours and myths" (CDC, 2020). Stigmatization is not new as it was evidenced in the case of previous epidemics as well as some wellknown diseases such as H1N1 swine flu (APA, 2020), 2014 Ebola outbreak (APA, 2020), MERS (APA, 2020), Tuberculosis (Mehra, 2020), Leprosy (Krishnatray, 2020) and Acquired Immuno-Deficiency Syndrome (Logie and Turan,2020). A classic example of stigmatization is the "Spanish flu" pandemic (Ranney, 2020). The probable causes of stigma related to COVID-19 are (Fayziev,2020):

Infodemics of misinformation through social media platform

Novelty of the virus

Decreased awareness levels among people Fear and xenophobia

Social stigma not only affects the mental health of the affected population but also the healthy minds of the healthy population. In the case of COVID-19, there are reports of death solely due to social stigma rather than the disease (Mehra, 2020). Tagging the disease along with a region or race or religion has been the foundation of social stigma.

In India, incidences of social stigma have been reported against people from a particular religion, region, and occupation (Ranney, 2020), especially against those involved in controlling outbreaks and with migrant workers during the COVID-19 pandemic (Perapaddan, 2020). Some people from a particular community were targeted after a religious congregation was associated with a cluster of outbreaks (Mazumdaru, 2020). Some persons belonging to a particular region of India were targeted as they physically resemble the Chinese population to a certain extent (Dixit, 2020, Roy et al., 2020). People who returned from foreign countries and heavily affected areas were also the subject of stigma (UNICEF, WHO and IFRC, 2020). At the international level, stigmatization was reported against a particular demographic group (Chinese and South Asians) (Chisholm, 2020). Besides affecting the mental health, social stigma also poses as a major hurdle in control of the disease as people are afraid of being stigmatized or ostracized (APA, 2020). This might prevent many from getting tested or fleeing from isolation or quarantine facilities (IANS, 2020b) which might increase mortality rate as it was observed in some regions of India (Press Trust of India,10May 2020; Tapadar, 2020). In the long run, stigma is also expected to affect the career prospects of international students (China Global Television Network, 2020). The Government ministry (Ministry of Health and Family Welfare, 2020), CDC (CDC, 2020), and UNICEF (UNICEF, WHO and IFRC, 2020) have released various statements and guidelines on beating this stigma. Some of the salient recommendations include to avoid tagging the virus with a region or particular race such as "Chinese virus" and to replace the words which can trigger negativity such as "infected" with "affected"(UNICEF, WHO 
and IFRC, 2020). Stereotypes and rumours need to be tackled with knowledge-based stigma reduction strategies (UNICEF, WHO, and IFRC, 2020), social influencers (UNICEF, WHO and IFRC, 2020), and strict regulations.

\section{Impact of COVID-19 pandemic on mental health of varying professions}

It is important to mention that the public groups and social identities are influenced by COVID-19 in different ways. Currently, there is an urgent need for the collection of quality data on mental health effects across the globe and mainly in the vulnerable population of different professions. An individual's reaction to an episode relies upon a few elements like their experience, the network they live in, and also their profession (Brennan et al., 2020). The effect of COVID-19 on cognition and brain function should be analysed.

\section{Health Care Workers (HCWs)}

In the current pandemic, ILO has estimated that about 136 million health and associated professionals are working in the frontline to fight against the virus (UN News, April 2020). WHO has announced that 22,073 HCWs are affected with COVID-19 from 52 countries on April 8, 2020 (WHO, 11 April 2020). Along with the physical illness, health care workers are also facing mental health problems such as anxiety, fear, psychological distress, panic attacks, depressive tendencies, sleep disturbances, helplessness, posttraumatic stress disorders (PTSD), avoidance of contact and stigma, personal isolation from family and fearing of contagion exposure to their family and friends (Rana et al., 2020;Pfefferbaum and North, 2020). Previous outbreak of SARS displayed the effect of PTSD in healthcare workers who worked in the SARS units who reported depression, anxiety, and frustration (nearly $58.9 \%$ population faced psychiatric disorders) (Wu et al., 2009; Mak et al., 2009). Mass quarantine of people could cause a collective sense like hysteria, fear, and anxiety in health workers working in inpatient and outpatient care, hospitals, primary care settings, communitybased hospitals, large tertiary care centers, assisted living facilities, nursing homes, and all isolation units (Fiorillo and Gorwood, 2020). It is difficult to get clarity on the aftermath of COVID-19 on the mental health of health care workers. Some early studies published had warned the world with darker feelings. A survey study conducted in China among 1,257 healthcare worker's cohort showed symptoms of mental illness like distress $(71.5 \%)$, anxiety (44.6\%), depression (50.4\%) and insomnia (34\%) (Lai et al., 2020). It is recommended by WHO that in addition to the efforts to prevent the disease at various levels, special attention is necessary for mental health issues of the community workers. Screening of psychiatric disorders like anxiety and depression in caregivers should be implemented (Greenberg et al., 2020).

In India, conservative estimation based on news reports showed that a minimum of 412 medical workers have been exposed to the disease, 826 professionals have undergone quarantine due to exposure and at least 96 doctors and 156 nurses have tested positive for COVID-19 (The Hindu, 2020). All these estimates ultimately cause a fear among HCWs and will lead to psychological stress. Despite the common mental health problems and psychosocial issues among healthcare workers, most health professionals do not receive systematic mental health care (Xiang et al., 2020). WHO recommends that handling of the pandemic situation with infection prevention and control measures should be complemented with occupational and safety health measures and other psychosocial support to the HCWs with adequate staffing 
facilities, clinical rotation to reduce the burnout risks and providing better working environment and to respect the ethical rights of the health workers (The Novel Coronavirus Pneumonia Emergency Response Epidemiology Team, 2020). A study on the consultation of COVID-19 related mental and psychological problems suggested a novel approach of Structured Letter Therapy. It is a kind of feasible and practically applicable psychological intervention approach. To acertain limit, this novel approach may also combine consultation with treatment and diagnosis. It is helping psychological consultants and psychiatrists to continue counselling on psychological and mental problems under strict quarantine measures, but it also has many disadvantages that need to be further addressed (Xiao, 2020).

\section{Farmers}

The poorer sections of society are consistently the hardest hit in any calamity or pandemic circumstances. The farmers and farmassociated workers are apparently at risk for stress development and other mental illnesses like depression, anxiety, fear, and suicide (Hovey and Seligman, 2006). Despite all the measures taken by the government, the continuing restrictions on movement of people and vehicular traffic have raised concerns on the negative associations of COVID-19 pandemic on the economy of the farm (Padhee and Carberry, 2020).

Supply chains are considered essential to the economic health and cross country-border trade and should be protected. The suicide rates in farmers may further increase during the COVID-19 pandemic. Uncertainly regarding arrival of essential workers seems to be increasing among land owners with regard to seasonal works (Patnaik, 2020). People living on agriculture and allied activities are mostly losing their income from informal employment during the lockdown period, ultimately leading to fear of financial insecurity.

The impact of pandemic is expected to be more on the farmers in developing countries (Jain et al., 2020) as the joblessness will not only affect economically but also cause other social and psychological stress. In countries like India, the month of May and June will be the harvesting period of rabi season and peak time for the transfer of commodities by designated government agencies (Padhee and Carberry, 2020). The existing mental health crisis in the agriculture sector is going to be worse and the farmers may struggle to operate farms and other associated businesses (West, 2020). Migrant workers who worked mostly on daily wages and were involved in diverse activities like harvesting and post-harvesting operations are in a sense of panic and anxiety about the future.

In fact, these migrant workers and landless labourers are the ones who are highly affected by the pandemic and are struggling the most to cope with the COVID-19 lockdown. Their struggles have been recorded in the images communicated by media wherein a large number of vagrant labourers were seen walking for a significant distance on expressways, with some of them having walked more than a 1000 kilometres to return to their villages (Pandey, 2020). Most of them were depressed physically as well as mentally. Farming is already becoming the most unpredictable industry and is responsible for increased morbidity and mortality due to psychological and physical stress, and related conditions. Since farmers often work in solitude, they may find trouble in taking decisions which are often followed by anxiety-related behaviours, irritability, sleep disturbances, hopelessness, excessive drinking, drug misuse finally leading to selfharm (West, 2020). 


\section{Entrepreneurs or businesspersons}

An entrepreneur or businessperson has been portrayed as somebody who energetically and inventively seeks after a thought from idea to completion because of a found need or challenge in the market. Entrepreneurs have an extraordinary impact have on our world economy and it is fundamentally significant that they work in a condition that operates in a state of optimum emotional and relational health (Desai, 2020). This is a hard time for everyone, but businesses are being particularly hurt by the impact of COVID-19. Many entrepreneurs and business leaders are approaching professional help to overcome the stress and anxiety caused by the pandemic. This could be the most difficult situation for the leaders of various domains. They are facing a double-edged sword of managing their firms and meeting the expectations of employees who are juggling between work and families. Mental health well-being institutions like 1 to 1 Help.net, Optum International, Fortis Healthcare, and Cosmos Institute of Mental Health and Behavioural Sciences (CIMBS) were flooded with calls from CEOs/CXOs of all size of enterprises and entrepreneurs against the usual monthly average of couple of calls (Economic Times, 2020). Entrepreneurs and other small business owners are remotely implementing the work and trying to continue the business operations but are sufficiently being affected with stress and anxiety. This unprecedented event is leaving a profound effect on the general psychological wellness. Other than coping with the anxiety of business continuity planning (BCP), business pioneers need to deal with their representatives just as their own families. Numerous business heads and business people are looking for proficient assistance to beat the pressure and nervousness initiated by the pandemic. Many business visionaries who feel responsible for the organization's future as well as for every single representative are being affected mentally. The pressure weighs heavily on the mental status of small business owners battling to help their customers, workers, and selves (Sweeney, 2020). Uncertainty and absence of control have led to an increase in significant levels of tension, short temper, changes in craving, sleep disturbances at times leading to panic attacks (Desai, 2020).

\section{Students}

Studies show that paces of nervousness, depression, stress, and anxiety in college students have risen significantly during the past few decades. The ongoing pandemic has left an already vulnerable population at a significantly much higher risk (OdriozolaGonzález, 2020). According to a survey, 42 per cent of the students are reconsidering their initial career choices (Edex Live, 2020). The pandemic is causing pressure, stress, anxiety and fear, which may be accelerated when telecommuting and being detached from colleagues and friends. Students are struggling academically, financially, and emotionally because of campus closures (Dennon, 2020). Different students respond to stress in different ways. Only one out of every odd student's house is genuinely and truly sheltered. Some may have a parent who was debilitated with corona virus, some have family members who are frontline workers and some students might be taking care of money-related worries at home especially if their parents are jobless (Bethany, 2020). A study suggested that students were encountering more elevated levels of uneasiness, higher levels of anxiety, stress, and depression due to the corona virus flareup. Being compelled to drop classes or disenroll, lacking sheltered and solid lodging, lacking access to a cell phone or $\mathrm{Wi}-\mathrm{Fi}$ and lacking dependable access to food and water are having more significant levels of nervousness, sorrow or worry than before (Dennon, 2020). 
Many students are stressed over ensuring themselves as they sense that they're socially disengaged, particularly if they live alone. Some students have expanded degrees of distress if they have pre-existing mental health concerns. Students from economically under-privileged families may see incremental mental pressure. Stigma due to race or ethnicity, language, culture, age, or disability has a likelihood of escalating mental health impact of COVID-19 (Pragholapati, 2020). These have increased stress on the students as is manifested as excessive anxiety, sadness, irritation, unhealthy eating or sleeping, excessive drinking and smoking, consumption of drugs. In such cases the perspective of students become narrow, prompting choices, based on fear which can be dangerous in the long haul. Students with underlying health conditions are also at an increased risk of having mental health concerns such as depression due to COVID-19 (Zhai and Du, 2020; Huckins et al., 2020).

\section{Evaluation of mental health}

Several parameters and screening tools have been developed by researchers to measure the mental wellbeing of individuals and the psychological impact of a disaster. Considering the difficulty in conducting face to face interview during the lockdown, the best way is to use online screening tools considering certain parameters.

\section{Beck Depression Inventory (BDI)}

A screening tool of 21 items to assess severity of depression. It was developed in 1961 (Beck et al., 1961) and updated and revised in the year 1996 (Beck et al., 1996) to be highly consistent with the depression or misery criteria suggested by DMS-IV. It also follows the same scale as that of BAI (Wang et al., 2011).

\section{Beck Anxiety Inventory (BAI)}

It contains total 21 parameters which assess anxiety or fear symptoms with intensity. A four-point scale ranging from 0 as "no symptoms' to 3 considered as 'severe' is used. Participants are monitored to observe symptoms over seven days (Che et al., 2006).

\section{Alcohol Use Disorder Identification Test (AUDIT)}

WHO has developed this tool for the identification of alcohol related consequences. AUDIT contains a total of 10 questions related to alcohol consumption. The respondent has to answer on a five-point scale (0-4) (Babor et al., 2001).

\section{Warwick Edinburgh Mental Wellbeing Scale (WEMWBS)}

The WEMWBS is a 14-item scale which assesses the mental health on positive aspects and covers subjective well-being and psychological functions. Respondent has to rank or order their feelings on a five-point Liker scale ranged from 1 (None of the time) to 5 (All the time) experience from the last two weeks (Dong et al., 2016).

Data generated from above screening tools can be subjected to statistical analysis and on the basis of inference drawn we can measure the mental health.

\section{Remedies to prevent the effect of COVID- 19 pandemic on mental health}

COVID-19 outbreak has not only caused the casualties but also had a greater impact on mental health of the total population. Selfisolation and lockdowns are vital strategies to control the spread of COVID-19; however, social isolation being a state of estrangement, in which social connections are absent or limited, may certainly lead to depression. 
Studies have established a link between social isolation leading to depression in humans (Matthews et al., 2016). Further, access to mental health resources are limited secondarily by social isolation which prevents many from getting the psychological help that is needed (Caulfield and George, 2020). In this context, mental health treatment during social isolation is very necessary and should be addressed immediately. People seeking remedies to already existing mental health problems should continue their treatments and should be aware of the current and aggravating symptoms. The alcoholics or drug addicts who are getting treatment should be aware of the spurt in feelings like isolation, fear and anxiety caused by COVID-19 outbreaks (WHO, 24 May 2020).

Considering the present situation of traffic limits and isolations, mental health services are to be provided online via telecare/healthcare facilitated by telecommunication technology. Mental health teams at various levels of health care should be established by using experts from multiple disciplines for the successful delivery of mental health to all patients and even health care workers. Services like psychological counselling to support the mental health must be provided by using the available digital technologies for patients and their families (Zhang et al., 2020). Both patients and their families should be sensitised with treatment plans, health status updates and progress reports. Quarantined individuals and health professionals are necessary to undergo regular clinical screening for anxiety depression, trauma, and suicidality by mental health workers. Initially the supportive online psychotherapy should be followed (Xiang et al., 2020). The mental health illness patients falling under 'severe' category should be treated with suitable less harmful pharmacological treatment. Caulfield and George (2020) has proposed to treat depression caused by COVID-19 by at-home neurotherapeutics tools available such as repetitive transcranial magnetic stimulation (rTMS), Transcranial direct current stimulation (tDCS), and Trans-auricular vagus nerve stimulation (taVNS).

Secondary mental health problems in health care workers can be dealt with urgent psychological crisis intervention model (PCIM) through the medium of online technology. PCIM consolidate teams of physicians, psychologists/mental health practitioners, psychiatrists, and social workers to deliver early psychological intervention to medical staff, families of patients, and to the patients (Rana et al., 2020). Epidemiological data on mental health consequences, psychiatric morbidity, psychological impact and psychosocial issues with the advent of COVID-19 and their screening, assessment, control, treatment plans, management, progress reports, health status updates, prevention and intervention are yet to be explored to respond to these challenges. Recently in Belgium, an online tool called "Everyone Ok" has been launched to support psychologically and educate their populations. A start-up named "Let's Talk" is operating on similar lines in India. Some countries like Belgium, New Zealand and Germany are introducing social bubble concept, the principle of this concept is allowing individuals to interact with only nearby or close contacts and step by step increase in bubble size in order to help people to get away from emotional distress (Wilson, 2020; The print, 2020).

With all the specific therapeutic strategies, the preparation of community health professionals to handle the situation is the key aspect in mental health care (Duan and Zhu, 2020). All such strategies through online mode may offer hope of accessibility to mental health services without any infection 
risk. These strategies greatly depend on the availability of infrastructure and trained personnel and ultimately on how the general public will accept it. However, these measures are yet to be validated in the targeted population (Rajkumar, 2020)

Some important tips and advice given by International organisations

Keep informed: Follow guidelines given by national and local authorities. Always listen to trusted news channels. Minimize news feeding i.e. reduce watching news that will make you distressed.

Have a routine: Follow daily routines as far as possible.

Social contact is important: Maintain physical distance and not social distance. One must always keep in regular contact with each other through telephone or other online channels.

Alcohol and drug use: Avoid using alcohol and drugs (WHO, 2020).

The themes of uncertainty, stigmatisation, and fear are not unusual during biological disasters and may act as hurdles to successful medicinal and mental health interventions (Xiang et al., 2020). Hence mental health assessment and relevant services are important goals in handling disaster caused by COVID-19 pandemic. Countries could implement the WHO's- Five Well-Being Index (WHO-5) as a short and self-reported measure of current mental wellbeing (Topp et al., 2015).

Figure.1 Statistics on mental health conditions before COVID-19 outbreak

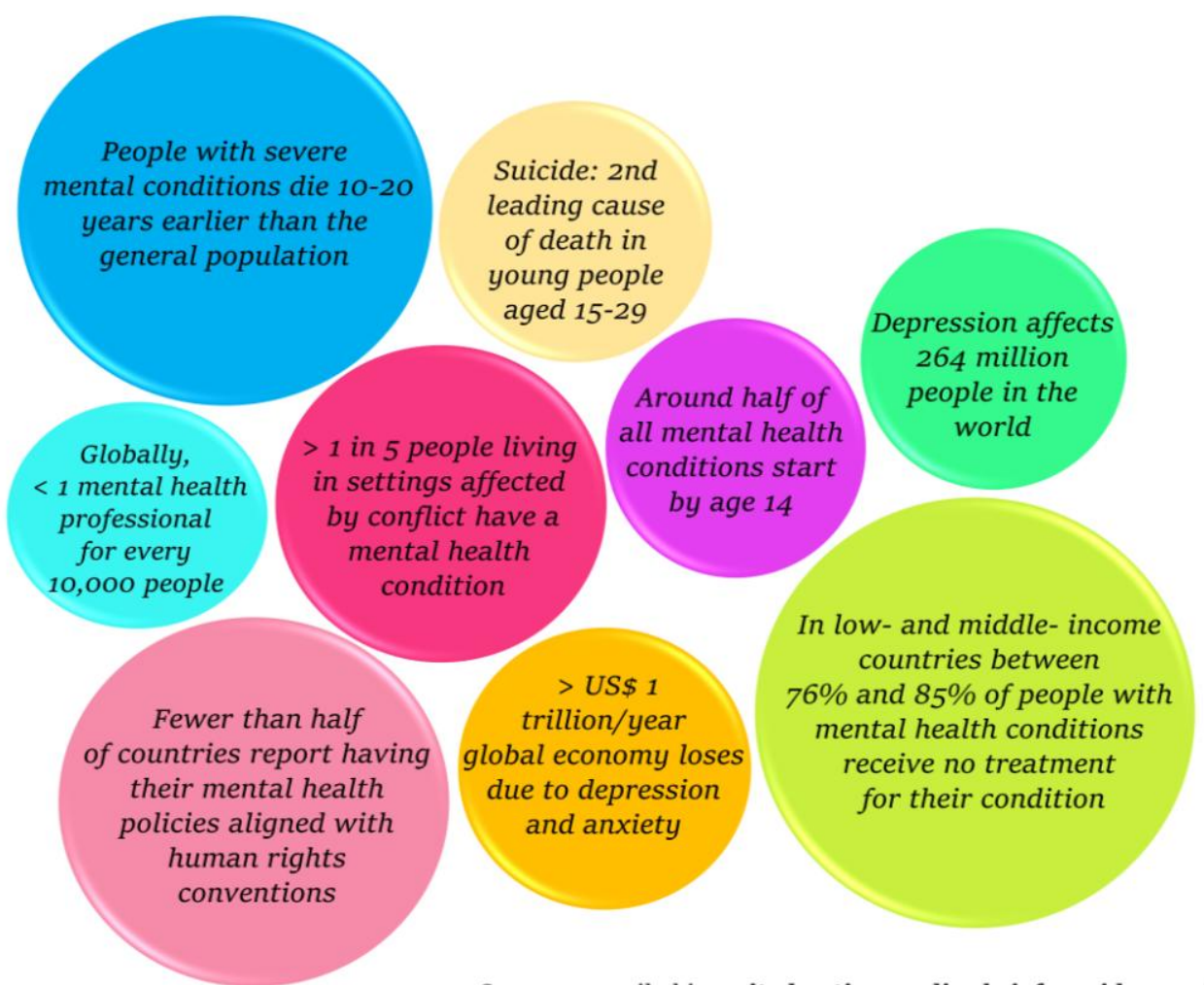

Source: compiled in united nations policy brief: covid-19 and the need for action on mental health, May 2020 
Figure.2 Situations, actions and reports on mental health of people across countries after COVID-19 outbreak

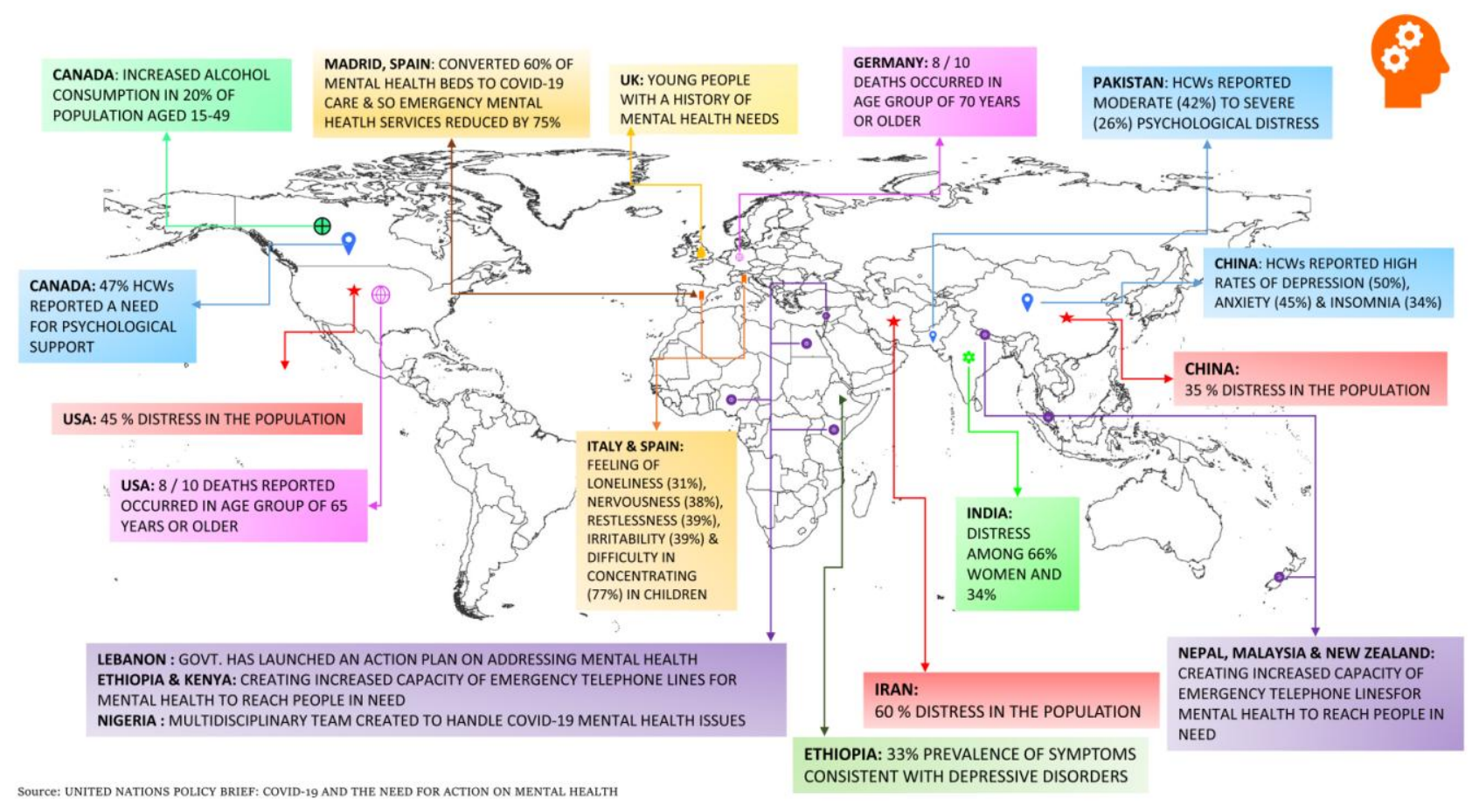

The United Nations had stipulated some guidelines to minimize health consequences of the pandemic:

Apply a whole-of-society approach to protect, promote, and care for mental health which includes inclusion of mental health and psychosocial considerations in national response plans, responding proactively to reducing pandemic-related adversities that are known to mental health and crafting all communications to be sensitive of their potential impact of people's mental health.

Ensure widespread availability of emergency mental health and psychosocial support by activities which include supporting community action that strengthen social cohesion and reduce loneliness; investing in remote delivery of medical health interventions; ensuring uninterrupted inperson care for severe mental health conditions by formally defining such case as essential services and protecting and promoting the human rights of people with mental disorders.

Support recovery from COVID-19 by building mental health services for the future which includes using the current momentum of interest in mental health to catalyze mental health reforms; achieving universal health coverage; building human resource capacity to deliver mental health and social care and organizing community-based services that protect and promote people's human rights (United Nations, 2020)

In conclusion, people can feel fluctuations in their own mental health during this global pandemic crisis with absence of their routine work and loneliness. Financial insecurity and domestic violence are forcing and turning the manageable problems into crisis among the common public. WHO can recommend the post traumatic treatment approaches like GTEP (Group Traumatic Episode Protocol) and R-TEP (Recent Traumatic Episode Protocol) 
as they were successful in France in mid 1990s in the after math of terrorist attacks and disaster. Psychiatrists and mental health workers across the world ought to know about the signs, their correlates, and strategies to manage them that encompass both the needs of specific populations. Countries like India that are short of mental health infrastructure could use the COVID-19 recovered patients to share their experiences to increase the confidence among others. Global and national organizations can collaborate to survey vulnerable groups and share the information worldwide. There is an urgent need of designing an appropriate study to survey the psychological disasters and its impact to mitigate the havoc cause by COVID-19 pandemic.

\section{References}

Adams-Prassl, A., Boneva, T., Golin, M. and Rauh, C., 2020. The Impact of the Coronavirus Lockdown on Mental Health: Evidence from the US (No. 2020030).

Adhikari, S.P., Meng, S., Wu, Y.-J., Mao, Y.-P., Ye, R.-X., Wang, Q.-Z., Sun, C., Sylvia, S., Rozelle, S., Raat, H. and Zhou, H., 2020. Epidemiology, causes, clinical manifestation and diagnosis, prevention and control of coronavirus disease (COVID-19) during the early outbreak period: a scoping review. Infect. Dis. $\begin{array}{lllll}\text { Poverty } & 17 & \text { (9), } 29.19 \quad \text { (http:// }\end{array}$ www.nhc.gov.cn, 2020).

American Psychological Association (APA), 2020, Viewed 25 March 2020, <https://www.apa.org/topics/covid-19bias>

Anne Dennon, 2020, Coronavirus and the Student Mental Health Crisis. Viewed 21 May 2020 , <https://www.bestcolleges.com/blog/coro navirus-and-student-mental-healthcrisis/>

Arnav Kashyap, 2020, Psychological effects of COVID-19, Viewed 22 April 2020,
$<$ https://www.thehillstimes.in/featured/ps ychological-effects-of-covid-19/>

Asmundson, G.J. and Taylor, S., 2020. How health anxiety influences responses to viral outbreaks like COVID-19: What all decision-makers, health authorities, and health care professionals need to know. J Anxiety Disord. 71. 102211-102211.

Babor, T.F., Higgins-Biddle, J.C., Saunders, J.B. and Monteiro, M.G., 2001. AUDIT: The Alcohol Use Disorders Identification Test, Guidelines for Use in Primary Care, 2nd ed. World Health Organization, Geneva, Switzerland.

Bao, Y., Sun, Y., Meng, S., Shi, J. and Lu, L., 2020. 2019-nCoV epidemic: address mental health care to empower society. The Lancet. 395(10224): e37-e38.

Beck, A.T., Steer, R.A., Ball, R. andRanieri, W.F., 1996. Comparison of Beck Depression Inventories-IA and-II in psychiatric outpatients. J. Pers. Assess. 67(3): 588-597.

Beck, A.T., Ward, C., Mendelson, M., Mock, J. and Erbaugh, J., 1961. Beck depression inventory (BDI). Arch Gen Psychiatry. 4(6): 561-571.

Benjamin, G. and Druss, M.D., 2020. Addressing the COVID-19 Pandemic in Populations With Serious Mental Illness.

Bethany, A. O. 2020, College students experience mental health decline from COVID-19 effects, survey finds. Here's how to get help, viewed 22 May 2020, < https://www.inquirer.com/health/coronavi rus/covid19-coronavirus-college-studentsmental-health-20200514.html>

Brennan, J., Reilly, P., Cuskelly, K. and Donnelly, S., 2020. Social Work, Mental Health, Older People and Covid19. Int. Psychogeriatr.:1-11.

Brooks, S.K., Webster, R.K., Smith, L.E., Woodland, L., Wessely, S., Greenberg, N. and Rubin, G.J., 2020. The psychological impact of quarantine and how to reduce it: rapid review of the evidence. Lancet. 395: 912-920.

Carlos, W.G., Dela Cruz, C.S., Cao, B., Pasnick, S and Jamil, S, 2020. Novel 
Wuhan (2019-nCoV) coronavirus. Am. J. Respir. Crit. Care Med. 201 (4): 7-8.

Caulfield, K.A. and George, M.S., 2020. Treating the mental health effects of COVID-19: The need for at-home neurotherapeutics is now. Brain Stimulation: Basic, Translational, and Clinical Research in Neuromodulation. 13(4): 939-940.

Centre for Disease Control and Prevention, 2020, About COVID-19, viewed 4 April, <https://faq.coronavirus.gov/basics/>

Chakrabarthi, A., 2020, April 8. Not a win-win situation - why we should not work from home after the Covid-19 lockdown. $<$ https://theprint.in/opinion/pov/not-awin-win-situation-why-we-should-notwork-from-home-after-the-covid19lockdown/397284/>

Che, H.-H., Lu, M.-L., Chen, H.-C., Chang, S.W.and Lee, Y.-J., 2006.Validation of the Chinese version of the beck anxiety inventory (In Chinese). Formosan J. Med. 10 (4): 447-454. https://doi.org/10.6320/FJM.2006.10(4).0 5

China Global Television Network, 2020, April 16). COVID-19 Global Roundup: How stigma harms the joint effort of the global community. Viewed 16 April 2020, $<$ https://news.cgtn.com/news/2020-0416/COVID-19-Global-Roundup-Onlysolidarity-not-stigma-can-save-livesPJwQMvPpDi/index.html>

Chisholm, N. J., 2020, March 13. AsianAmerican leaders condemn COVID-19 racism, viewed 13 March 2020, <https://www.colorlines.com/articles/asia n-american-leaders-condemn-covid-19racisms>

Constitution of the World Health Organization, 2005, In: World Health Organization: Basic documents. 45th ed. Geneva: World Health Organization; 2005.

CoronavirusDisease-19, Republic of Korea, 2020. Viewed 21 March, 2020, <http://ncov.mohw.go.kr/bdBoardList_Re al.do?brdId $=1 \&$ brdGubun $=11 \&$ ncvContS eq $=\&$ contSeq $=\&$ board_id=\&gubun $=>$ Ac
cessed21March,2020>

Cucinotta, D. and Vanelli, M., 2020. WHO declares COVID-19 a pandemic. Acta Biomed. Atenei Parmensis. 91(1):157160.

Cullen, W., Gulati, G. and Kelly, B.D., 2020. Mental health in the Covid-19 pandemic. QJM: Int. J. Gen. Med.113(5): 311-312.

Deborah Sweeny., 2020. How can entrepreneurs take care of their mental health during the corona virus?, viewed 23 May 2020, <https://www.score.org/blog/how-canentrepreneurs-take-care-their-mentalhealth-during-coronavirus>

Dixit, R., 2020, March 28. Northeast people battle racism amid coronavirus pandemic, viewed 28 March 2020, <https://www.theweek.in/news/india/202 0/03/28/coronavirus-pandemic-fuelsracism-against-northeast-people.html>

Dong, A., Chen, X., Zhu, L., Shi, L., Cai, Y., Shi, B., Shao, L. andGuo, W., 2016. Translation and validation of a Chinese version of the Warwick-Edinburgh Mental Well- being Scale with undergraduate nursing trainees. J. Psychiatr. Ment. Health Nurs. 23: 554560. https://doi.org/10.1111/jpm.12344.

Du Toit, A., 2020. Outbreak of a novel coronavirus. Nat. Rev. Microbiol. 18 (3), 123.

Duan, L. and Zhu, G., 2020. Psychological interventions for people affected by the COVID-19 epidemic. Lancet Psychiatry, 7(4): 300-302.

Edex Live, 2020, 42 per cent students are reconsidering their career choices amid the pandemic, says survey, viewed 23 April

$2020,<$ https://www.edexlive.com/news/2 020/apr/23/42-per-cent-students-arereconsidering-their-career-choices-amidthe-pandemic-says-survey-11514.html>

Fayziev, S. F., 2020. The problem of social stigma during a pandemic caused by COVID-19. Int. J. Adv. Sci. Technol. 29(7): 660-664.

Fiorillo, A. and Gorwood, P., 2020. The consequences of the COVID-19 pandemic 
on mental health and implications for clinical practice. EurPsychiatry.63(1).

Funk, M., Gale, E., Grigg, M., Minoletti, A. and Yasamy, M.T., 2005. Mental Health Promotion: An Important Component of National Mental Health Policy. Promoting Mental Health.

Gao, J., Zheng, P., Jia, Y., Chen, H., Mao, Y., Chen, S., Wang, Y., Fu, H. and Dai, J., 2020. Mental health problems and social media exposure during COVID-19 outbreak. Plos one. 15(4), e0231924.

Garg, K., Kumar, C.N. and Chandra, P.S., 2019. Number of psychiatrists in India: Baby steps forward, but a long way to go. Indian J Psychol.61(1): 104.

Giltay, E.J., Geleijnse, J.M., Zitman, F.G., Hoekstra, T. and Schouten, E.G., 2004. Dispositional optimism and all-cause and cardiovascular mortality ina prospective cohort of elderly Dutch men and women. Arch. Gen. Psychiatry. 61(11):1126-1135.

Goyal, K., Chauhan, P., Chhikara, K., Gupta, P. and Singh, M.P., 2020. Fear of COVID 2019: First suicidal case in India!. Asian J Psychiatr. 49, 101989.

Greenberg, N., Docherty, M., Gnanapragasam, S. andWessely, S., 2020. Managing mental health challenges faced by healthcare workers during covid-19 pandemic. Bmj. 368.

Gunnell, D., Appleby, L., Arensman, E., Hawton, K., John, A., Kapur, N., Khan, M., O'Connor, R.C., Pirkis, J., Caine, E.D. and Chan, L.F., 2020. Suicide risk and prevention during the COVID-19 pandemic. Lancet Psychiat. 7(6): 468471.

Ho, C.S., Chee, C.Y. andHo, R.C., 2020. Mental health strategies to combat the psychological impact of COVID-19 beyond paranoia and panic. Ann Acad Med Singapore. 49(1): 1-3.

Holmes, E.A., O'Connor, R.C., Perry, V.H., Tracey, I., Wessely, S., Arseneault, L., Ballard, C., Christensen, H., Silver, R.C., Everall, I. and Ford, T., 2020. Multidisciplinary research priorities for the COVID-19 pandemic: a call for action for mental health science. The Lancet Psychiatry. 7(6): 547-560.

Hovey, J.D. and Seligman, L.D., 2006. The mental health of agricultural workers. In Agricultural medicine.: 282-299. Springer, New York, NY.

Huang, C., Wang, Y., Li, X., Ren, L., Zhao, J., Hu, Y., Zhang, L., Fan, G., Xu, J., Gu, X., Cheng, Z., Yu, T., Xia, J., Wei, Y., Wu, W., Xie, X., Yin, W., Li, H., Liu, M., Xiao, Y., Gao, H., Guo, L., Xie, J., Wang, G., Jiang, R., Gao, Z., Jin, Q., Wang, J. and Cao, B., 2020. Clinical features of patients infected with 2019 novel coronavirus in Wuhan, China. Lancet. 395 (10223): 497-506.

Huckins, J., Hedlund, E.L., Rogers, C., Nepal, S.K., Wu, J., Obuchi, M., Murphy, E.I., Meyer, M.L., Wagner, D.D., Holtzheimer, P.E. and Campbell, A.T., 2020. Mental Health and BehaviorDuring the Early Phases of the COVID-19 Pandemic: A Longitudinal Mobile Smartphone and Ecological Momentary Assessment Study in College Students.

IANS, 2020a, Work from home could be harmful for employees, warns Microsoft CEO Satya Nadella, viewed on 19 May 2020,<https://www.livemint.com/compan ies/news/work-from-home-could-beharmful-for-employees-warns-microsoftceo-satya-nadella11589870346435.html>

IANS, 2020b, Social stigma forcing patients to avoid screening in India. Retrieved from, viewed 16 March 2020, <https://www.livemint.com/news/india/so cial-stigma-forcing-coronavirus-patientsto-avoid-screening-in-india11584359972347.html>

Kim, S.W. and Su, K.P., 2020. Using psycho neuro immunity against COVID-19. Brain, behavior, and immunity.

Kotfis, K., Williams Roberson, S., Wilson, J.E., Dabrowski, W., Pun, B.T. and Ely, E.W., 2020. COVID-19: ICU delirium management during SARS-CoV-2 pandemic. Critical Care, 24: 1-9.

Krishnatray, P, 2020, COVID-19 leading a new 
wave of social stigma, viewed 12 May 2020, <https://thewire.in/society/covid19-social-stigma>

Kumar, A. and Nayar, K.R., 2020. COVID 19 and its mental health consequences. J. Ment. Heal. 1-2.

Lai, J., Ma, S., Wang, Y., Cai, Z., Hu, J., Wei, N., Wu, J., Du, H., Chen, T., Li, R. and Tan, H., 2020. Factors associated with mental health outcomes among health care workers exposed to coronavirus disease 2019. JAMA network open. 3(3): e203976-e203976.

Lee, K., Sahai, H., Baylis, P. and Greenstone, M., 2020. Job Loss and Behavioral Change: The Unprecedented Effects of the India Lockdown in Delhi. University of Chicago, Becker Friedman Institute for Economics Working Paper, (2020-65).

Lewis T, 2020, Smoking or vaping may increase the risk of a severe coronavirus infection. Sci Am. Published 2020. Viewed March 26, 2020, <https://www.scientificamerican.com/arti cle/smoking-or-vaping-may-increase-therisk-of-a-severe-coronavirus-infection1/>

Lima, C.K.T., de Medeiros Carvalho, P.M., Lima, I.D.A.S., de Oliveira Nunes, J.V.A., Saraiva, J.S., de Souza, R.I., da Silva, C.G.L. and Neto, M.L.R., 2020. The emotional impact of Coronavirus 2019-nCoV (new Coronavirus disease). Psychiatry Res. 112915.

Logie, C.H. and Turan, J.M., 2020. How do we balance tensions between COVID-19 public health responses and stigma mitigation? Learning from HIV research. AIDS Behav. 1.

Love, J.S., Blumenberg, A. and Horowitz, Z., 2020. The Parallel Pandemic: Medical Misinformation and COVID-19: Premium non nocere. J Gen Intern Med. 1-2.

Mak, I.W.C., Chu, C.M., Pan, P.C., Yiu, M.G.C. and Chan, V.L., 2009. Long-term psychiatric morbidities among SARS survivors. Gen Hosp Psychiatry. 31(4): 318-326.

Matthews, T., Danese, A., Wertz, J., Odgers, C.L., Ambler, A., Moffitt, T.E. and
Arseneault, L., 2016. Social isolation, loneliness and depression in young adulthood: a behavioural genetic analysis. Soc Psych PsychEpid. 51(3): 339-348.

Mazumdaru, S., 2020, Religious tension in India aggravated by coronavirus. Viewed 21 April 2020, <https://www.dw.com/en/religioustension-in-india-aggravated-bycoronavirus/a-53195228>

Mehra, C., 2020, Covid-19 stigma is a major roadblock in India's path to recovery. Here's how to beat it, viewed 17 April 2020 , https://scroll.in/article/959153/covid-19stigma-is-a-major-roadbloack-in-indiaspath-to-recovery-heres-how-to-beat-it>

Ministry of Health and Family Welfare, 2020, Addressing Social stigma associated with COVID-19. Viewed 5 April 2020, <https://www.mohfw.gov.in/pdf/Addressi ngSocialStigmaAssociatedwithCOVID19. pdf>

Naik, A., 2020, As India's lockdown ends, a mental health crisis is just beginning, viewed 18 May 2020, <https://www.weforum.org/agenda/2020/ 05/indias-lockdown-ends-mental-healthcrisis-beginning/>

National Health Commission, China, 2020. Viewed 25 May 2020, <http://en.nhc.gov.cn/search.html?search Text=mental+illness $>$

Odriozola-González, P., Planchuelo-Gómez, Á., Irurtia, M.J. and de Luis-García, R., 2020. Psychological effects of the COVID-19 outbreak and lockdown among students and workers of a Spanish university. Psychiatr. Res.113108.

Oliver Kamm, 2020, There is no reason to expect an epidemic of mental illness in the wake of this crisis, viewed 7 May 2020, <https://capx.co/there-is-no-reasonto-expect-an-epidemic-of-mental-illnessin-the-wake-of-this-crisis/>

Ornell, F., Schuch, J.B., Sordi, A.O. and Kessler, F.H.P., 2020. "Pandemic fear" and COVID-19: mental health burden and strategies. Braz J Psychiatry. 42(3): 232- 
235.

Padhee, A. K. and Carberry, P., 2020. Containing COVID-19 impacts on Indian agriculture.

<https://www.icrisat.org/containingcovid19-impacts-on-indianagriculture/b.>

Parveen Jain, D., Baghla, K. and Aditya, R., 2020. Effect of corona/COVID19 on the agricultural sector in India. World, 2258909, 154388

Patnaik, N.M., 2020, April 23. The effects of COVID19 and its Psychological impact on people from different strata in India. Agricultural Extension in South Asia.

Perapaddan, B. S., 2020. Preventing stigma related to COVID-19 requires fullthroated campaign, says expert Gita Sen. Retrieved from, viewed 31 March 2020, $<$ https://www.thehindu.com/news/nationa 1/preventing-stigma-related-to-covid-19requires-full-throated-campaign-saysexpert-gita-sen/article31215075.ece>

Pfefferbaum, B. and North, C. S., 2020. Mental health and the Covid-19 pandemic. N Engl J Med.

Pragholapati, A., 2020. COVID-19 IMPACT ON STUDENTS.

Press Trust of India, 2020, April 18. Coronavirus: Telangana launches helpline to address psychological issues during lockdown,

<https://www.deccanherald.com/national/ south/coronavirus-telangana-launcheshelpline-to-address-psychological-issuesduring-lockdown-826881.html>

Press Trust of India, 2020, April 29. COVID-19 could lead to 7 million unintended pregnancies as access to contraceptives disrupted: UN study, $<$ https://www.thehindu.com/news/internat ional/covid-19-could-lead-to-7-millionunintended-pregnancies-as-access-tocontraceptives-disrupted-unstudy/article31460311.ece>

Press Trust of India, 2020, May 10. Stigma reason for high COVID-19 mortality rate in Ahmedabad: AIIMS chief, $<$ https://www.ndtv.com/india- news/coronavirus-stigma-reason-for-highcovid-19-mortality-rate-in-ahmedabadaiims-chief-2226177>

Rajkumar, R.P., 2020. COVID-19 and mental health: A review of the existing literature. Asian J Psychiatr. 102066.

Rana, W., Mukhtar, S. and Mukhtar, S., 2020. Mental health of medical workers in Pakistan during the pandemic COVID-19 outbreak. Asian. J Psychiatry. 51.

Ranney, M., 2020, April 20. Fight the Disease, not the warrior. $<$ https://thriveglobal.in/stories/fight-thedisease-not-the-warrior/>

Roy, D., Tripathy, S., Kar, S.K., Sharma, N., Verma, S.K. andKaushal, V., 2020. Study of knowledge, attitude, anxiety \& perceived mental healthcare need in Indian population during COVID-19 pandemic. Asian. J Psychiatry. 102083.

Sandy West, 2020. Economic Blow of The Coronavirus Hits America's Already Stressed Farmers, $<$ https://khn.org/news/pandemiceconomic-blow-hits-americas-alreadystressed-farmers/>

Schimmenti, A., Billieux, J. andStarcevic, V., 2020. The four horsemen of fear: An integrated model of understanding fear experiences during the COVID-19 pandemic. Clin. Neuropsychiatry. 17(2): 41-45.

Sharma, A.J. and Subramanyam, M.A., 2020. Psychological impact of Covid-19 lockdown in India: Different strokes for different folks. Med Rxiv.

Shikha Desai, 2020. Entrepreneurs combat stress to maintain mental health, $<$ https://timesofindia.indiatimes.com/lifes tyle/relationships/work/entrepreneurscombat-stress-to-maintain-mentalhealth/articleshow/74826847.cms>

Singh, S., 2020, May 9. Covid-19 \& lockdown accelerate online gaming, $<$ https://economictimes.indiatimes.com/te ch/internet/covid-19-lockdownaccelerate-onlinegaming/articleshow/75640044.cms?from $=\mathrm{mdr}>$ 
Starcevic, V., 2017. Cyberchondria: challenges of problematic online searches for healthrelated information. Psychother Psychosom. 86(3): 129-133.

Tapadar, P., 2020, May 8. Social stigma, low testing behind WB"s high COVID-19 mortality rate: experts, $<$ https://www.outlookindia.com/newsscro 11/social-stigma-low-testing-behind-wbshigh-covid19-mortality-rateexperts/1827704>

Taylor, S. andAsmundson, G.J., 2004. Treating health anxiety: A cognitive-behavioral approach. Guilford Press.

The Economic Times, 2020. Entrepreneurs, CEOs seek professional help to cope with Covid-19 stress, <https://economictimes.indiatimes.com/n ews/company/corporatetrends/entrepreneurs-ceos-seekprofessional-help-to-cope-with-covid-19stress/articleshow/74924931.cms?from= mdr>

The Hindu, 2020. How many doctors and nurses have tested positive for coronavirus in India? Viewed 23 May 2020 , <https://www.thehindu.com/data/howmany-doctors-and-nurses-have-testedpositive-for-coronavirus-inindia/article31410464.ece>

The Novel Coronavirus Pneumonia Emergency Response Epidemiology Team. 2020. The epidemiological characteristics of an outbreak of 2019 Novel Coronavirus Diseases (COVID-19) - China, 2020. <http://weekly.chinacdc.cn/en/article/id/e 53946e2-c6c4-41e9-9a9b-fea8db1a8f51>

The print, 2020. Social bubbles - how Belgium, New Zealand \& Germany are helping citizens meet friends, family, viewed 24 May 2020, $<$ https://theprint.in/world/social-bubbleshow-belgium-new-zealand-germany-arehelping-citizens-meet-friendsfamily/419804/>

The Telegraph, 2020. Coronavirus: Indian man' died by suicide' after becoming convinced he was infected. https://www.telegraph.co.uk/globalhealth/science-and-

disease/coronavirusindian- man-diedsuicide-becoming-convinced-infected/ (Accessed 14 Feb 2020).

Topp, C.W., Ostergaard, S.D., Sondergaard, S. and Bech, P., 2015. The WHO-5 WellBeing Index: a systematic review of the literature. Psychother Psychosom. 84(3): 167-176.

UN News, 2020. COVID-19: impact could cause equivalent of 195 million job losses, says ILO chief. viewed 25 May 2020 ,

<https://news.un.org/en/story/2020/04/10 61322>

UNICEF, WHO AND IFRC, 2020, February 24). Social stigma associated with COVID-19. Viewed 24 February 2020, <https://www.unicef.org/media/65931/fil e/Social\%20stigma\%20associated\%20wit $\mathrm{h} \% 20$ the $\% 20$ coronavirus $\% 20$ disease $\% 20$ 2019\%20(COVID-19).pdf>

United Nations, 2020. Policy Brief: COVID-19 and the Need for Action on Mental Health , <https://www.un.org/sites/un2.un.org/file s/un_policy_briefcovid_and_mental_healt h_final.pdf>

UzmiAthar, 2020. Blind people fear relaxation of lockdown, wonder impact of social distancing on their lives. Viewed 7 may 2020 ,

$<$ https://www.businessinsider.in/india/ne ws/blind-people-fear-relaxation-oflockdown-wonder-impact-of-socialdistancing-on-theirlives/articleshow/75593701.cms>

van der Kolk, B., 2015. The Body Keeps the Score: Mind, Brain and Body in the Transformation of Trauma. New York, NY: Penguin Random House

Vijayaraghavan, P. and SINGHAL, D., 2020. A Descriptive Study of Indian General Public's Psychological responses during COVID-19 Pandemic Lockdown Period in India.

Vikas Pandey, 2020. India's poorest 'fear hunger may kill us before coronavirus', viewed2020, March 25. BBC News. 
<https://www.bbc.com/news/world-asiaindia-52002734>

Wang, Z., Yuan, C.M., Huang, J., Li, Z.Z., Chen, J., Zhang, H.Y., Fang, Y.R. and Xiao, Z.P., 2011. Reliability and validity of the Chinese version of Beck Depression Inventory-II among depression patients. Chinese Mental Health Journal.

Wilson, S., 2020. Pandemic leadership: Lessons from New Zealand's approach to COVID-19. Leadership, 1742715020929151.

Wind, T.R., Rijkeboer, M., Andersson, G. and Riper, H., 2020. The COVID-19 pandemic: The 'black swan'for mental health care and a turning point for ehealth. Internet interventions.

World Health Organization situation report-82. 11, April, 2020. Viewed 17 May 2020, <https://www.who.int/docs/defaultsource/coronaviruse/situationreports/20200411-sitrep-82-covid-19.pdf $>$

World Health Organization, 11 March 2020. WHO Director-General's opening remarks at the media briefing on COVID19-. Geneva, Switzerland.

World Health Organization, 2020, March 18. Mental health and psychosocial considerations during COVID-19, $<$ https://www.who.int/docs/defaultsource/coronaviruse/mental-healthconsiderations.pdf?sfvrsn=6d3578af_2> World Health Organization, 2020. Looking after our mental health. Viewed 24 May 2020 , $<$ https://www.who.int/newsroom/campaigns/connecting-the-worldto-

combatCoronavirus/healthyathome/health yathome---mental health?>

Wu, P., Fang, Y., Guan, Z., Fan, B., Kong, J., Yao, Z., Liu, X., Fuller, C.J., Susser, E., $\mathrm{Lu}$, J. and Hoven, C.W., 2009. The psychological impact of the SARS epidemic on hospital employees in China: exposure, risk perception, and altruistic acceptance of risk. Can $\mathrm{J}$ Psychiatry. 54(5): 302-311.

Xiang, Y.T., Yang, Y., Li, W., Zhang, L., Zhang, Q., Cheung, T. and Ng, C.H., 2020. Timely mental health care for the 2019 novel coronavirus outbreak is urgently needed. Lancet Psychiatry. 7(3): 228-229.

Xiao, C., 2020. A novel approach of consultation on 2019 novel coronavirus (COVID-19)-related psychological and mental problems: structured letter therapy. Psychiatry Investig.17(2), 175.

Zhai, Y. and Du, X., 2020. Addressing collegiate mental health amid COVID-19 pandemic. Psychiatr. Res.113003.

Zhang, K., Zhou, X., Liu, H. and Hashimoto, K., 2020. Treatment concerns for psychiatric symptoms in patients with COVID-19 with or without psychiatric disorders. Br J Psychiatry. 1-1.

\section{How to cite this article:}

Diksha Purushottam Gourkhede, Karthikeyan Ravichandran, Srinivas Kandhan, Vemula Prasastha Ram, B. Dhayananth, G. K. Megha and Suman Kumar, M. 2020. COVID-19: Mental Health Issues and Impact on Different Professions. Int.J.Curr.Microbiol.App.Sci. 9(07): 29943013. doi: https://doi.org/10.20546/ijcmas.2020.907.353 